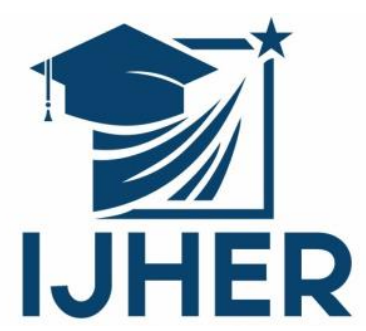

International Journal of Humanities and Educational Research

Volume 1, Issue 1, December 2019, p.31-39

İstanbul / Türkiye

\title{
The impact of colloquialism on the system of religious and social values - problems and Solutions \\ http://dx.doi.org/10.47832/2757-5403.1-2
}

\section{Muhammad Fawzi ABDULLAH'}

\section{Shamim Radhi ABD $^{2}$}

ISSN: 2757-5403

Article Information

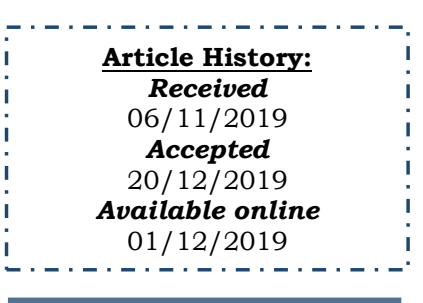

This article has been scanned by iThenticat No plagiarism detected

Copyright $@$ Published by Rimak Journal, www.rimakjournal.com

Rimar Academy, Fatih, Istanbul, 34093 Turkey All rights reserved

\begin{abstract}
This research aims to try to reveal the penetration of the local colloquial dialects that arose after the decline of the tide of Standard Arabic and the decline of its use by the Arabic speaker in his daily life and social dealings, limited to written speech in the sacred texts or educational curricula in the classical Arabic language at different levels of our linguistic life in Literature, journalism, meetings, transactions and laws, and this penetration into the media can be mainly monitored, as well as various forms of poetry and prose penetration into literature and others, and the research provided an accurate description of this phenomenon and how to deal with it in a practical way that keeps pace with the times, while preserving the classical language.

The research came in an introduction and two studies that dealt with this phenomenon in terms of problems and effective solutions according to solid scientific foundations.
\end{abstract}

Keywords: colloquial language, classical language, religious values, social values.

\footnotetext{
${ }^{1}$ Dr., Iraqia University, College of Arts. Mahmood.alkubaisy@gmail.com

2 Dr., The college of open education.
}

\section{IJHER}

International Journal of Humanities and Educational Research

Volume 1, Issue 1, December 2019, p.31-39 


\section{أثرز العامية في منظومة القيم الاينية والاجتماعية

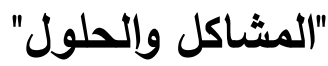

3

شميم عبد 4

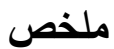

يهدف هذا البحث إلى محاولة الكثف عن تغلغل اللهجات العامية المحلية التي نثأت بعد تقهقر مدِّ العربية الفصحى واندثار استعمالها من المتكلم العربي في حياته اليومية ومعاملاته الاجتماعية، مقتصراً على الكلام

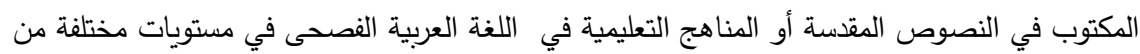

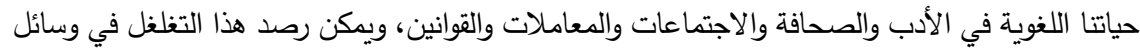
الإعلام بالدرجة الأساس، وكذلك تغلغلت إلى الأدب بصور مختلفة من شعر ونثر وغيره، وقد قدّم البحث

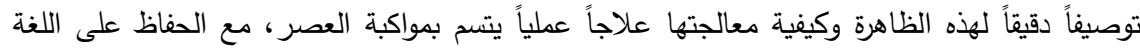

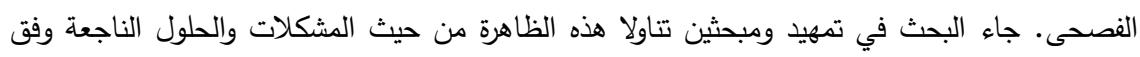

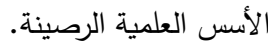
الكلمات المفتاحية: اللغة العامية، اللغة الفصحى، القيم الدينية، القيم الاجتماعية.

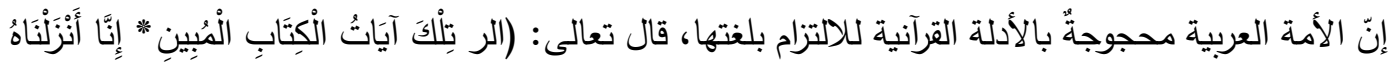

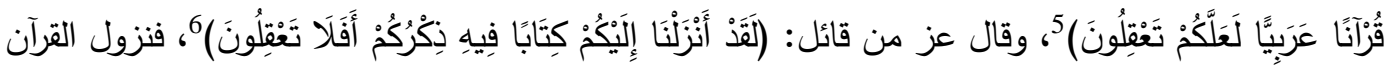

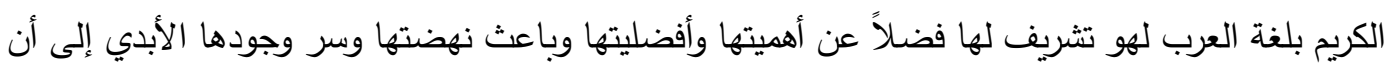
يرث الله الأرض ومن عليها. والعربية الفصحى هي أهم مقومات شخصيتتا وهويتنا ومستودع القيم والتجارب التي انتقلت إلينا من أسلافنا فضلاً عن أنّها لغة القرآن، ولها دور كبير في ترسيخ الفكر العربي وتعزيز الروابط بين أبناء الأمة العربية. وقد واجهت العربية الفصحى تحديات كبيرة في العصر الحديث بغية القضاء عليها، ومن أبرز هذه التحديات

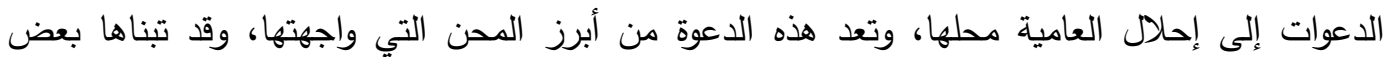

Mahmood.alkubaisy@gmail.com الدكتور : محمود فوزي عبد الله، كليَّة الآداب، الجامعة العراقية. 4 الدكتور : شميم راضي عبد، كلية التربية الدفتوحة، العراق. 5 سورة يوسف: الآية 2. 6 سورة الأنبياء: الآية 10.

\section{IJHER}

International Journal of Humanities and Educational Research

Volume 1, Issue 1, December 2019, p.31-39 
المستشرقين ومن تأثّر بهم من العرب بذريعة أنهّا لغة الثعب كلّه، وتعبّر عن مشاعرهم وأفكارهم، واتخذ بعضهم من هذا شعاراً لهه، فقالوا: "إنّ اللغة الحقيقية هي اللغة التي يستخدمها الناس فعلاً، لا التي يعتقد

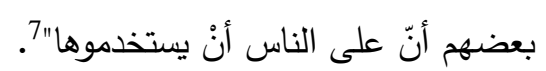
وعلى إثر هذا انعقد مؤتمر في لبنان في سنة 1973م، وضمَّ عدداً من أساتذة الجامعات في أمريكا وأوربا

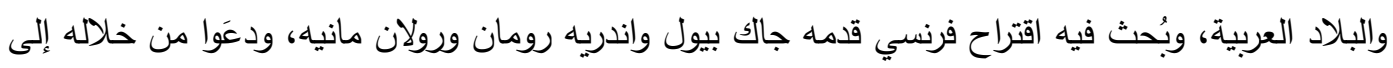

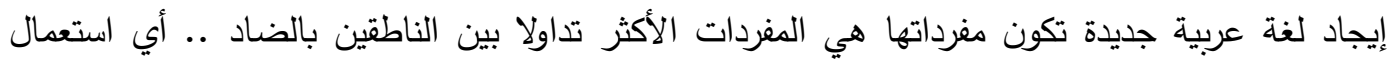

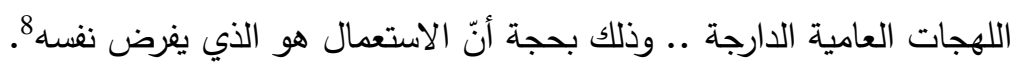
فإذا ما انتشرت اللغة العامية، وأصبحت هي اللغة الرسمية في المخاطبات والتخاطب بين الناس؛ أدى هذا لئها إلى عدم فهم آيات كتاب الله، والابتعاد عن فهم الأحكام التي تعالج القيم المجتمعية؛ لأنّ القرآن الكريم هو دستور الحياة، وفي هذا يثير جرجي زيدان إلى مدى تأثير القران الكريم في حياة المسلمين المعاشية والاجتماعية، فيقول: "بل هو أي القرآن الكريم أثد تأثيراً في المسلمين من سواه؛ لأثهّم مكلفون في حداثتهم

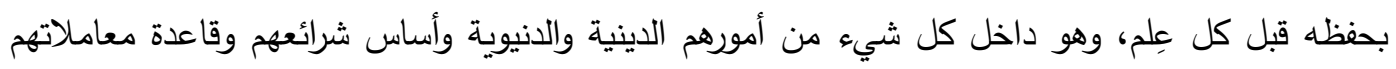
اليومية وأحوالهم العائلية حتى الطعام واللباس والثراب والنوم والغسل وكل شيء دئ يمكن استتباطه منه ويوجد

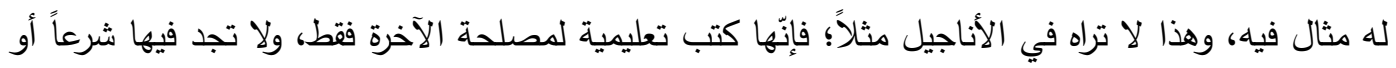

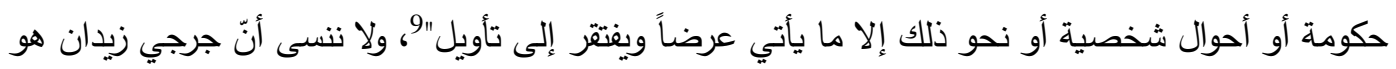

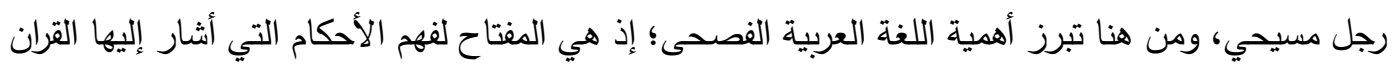
الكريم والتي لها أثر كبير في منظومة القيم الاجتماعية في اختيار أحد النجدين إمّا شاكراً وإمّا كفوراً.

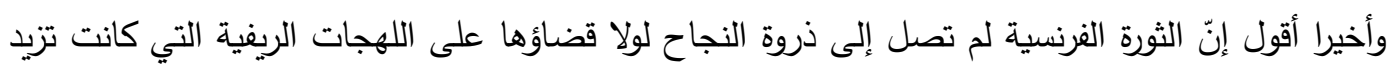
عن ثلاثين لهجة، ولقد وصف الأب غريغوار في تقرير لله حول ضرورة توفير الوسائل للقضاء على اللهجات الريفية وإضفاء الطابع العالمي على اللغة الفرنسية ومن هنا أقول لا عودة إلى رأس الهرم، ولا يمكن أن نعود إلى قمة الجبل كما كان أسلافُنا ما لم نحتذِ بمقولة الأب غريغوار في القضاء على اللهجات العامية.

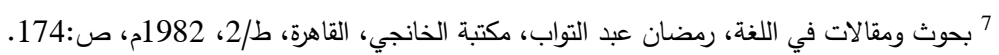

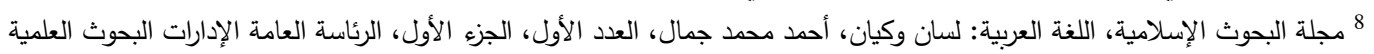

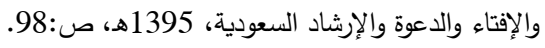
9 تاريخ آداب اللغة العربية، جرجي زيدان، دار الهلال، القاهرة، 16/2.

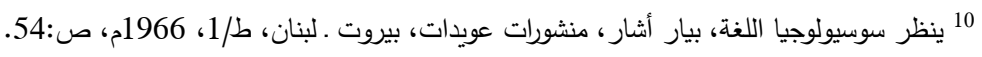

\section{IJHER}

International Journal of Humanities and Educational Research

Volume 1, Issue 1, December 2019, p.31-39 


\section{التمهيد:}

الفصحى في اللغة والاصطلاح:

لغة: قال ابن فارس (ت 395 هـ): "فصح: الفاء والصاد والحاء أصل يدل على خلوص في شيء ونقاءٍ من الثوب، من ذلك: اللسان الفصيح: الطليق، والكلام الفصيح: العربي، والأصل أفصح اللبن: سكنت رغوته، وأفصح الرجل: تكلّم العربية" 11. وأثار ابن منظور (ت 711هـ) إلى أنّ الفصاحة هي البيان"12. وأمّا الفصاحة اصطلاحاً: "فهي لغة القرآن والأدب، وهي لغة خاصة سليمة من كل عيب، لا يخالطها لفظ الف الفا عامي أو أعجمي، خلاف العامية"13.

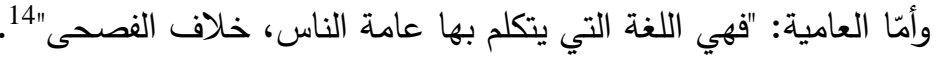
مظاهر تبني العامية في هذا العصر ومخاطرها

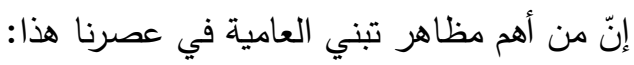

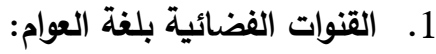

الخطر الكبير على اللغة العربية الفصحى يأتي في الوقت الحالي من الفضائيات والإذاعات العربية التي تقوم بنشر برامج ثقافية وعلمية وأدبية، وكذلك الإعلانات باللغة العامية وباللغة الأجنبية البعيدة عن الفصحى، وهذه خطيئة يجب أن لا تقع فيها وسائل الإعلام التي من المفترض أن تعمل على تطوير اللغة العربية وتحسينها،

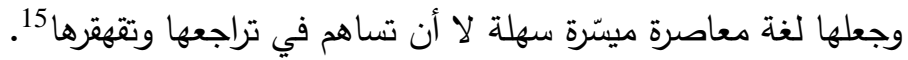
ولابد من الذكر أنّ الخطورة الأكبر في هذا الجانب هو عمل الأفلام الكارتونية باللغة العامية للأطفال، وهذا يجب التتبّه إليه وعمل على الحد منه.

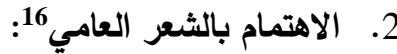
وهذا الخطر الثاني الذي يهدد العربية الفصحى؛ إذ إنَّ الكلامَ عندما يكون موزوناً ومقفى فإنّه يكون الأسهل للانتشار من غيره.

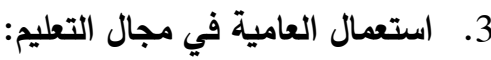
والأخطر من ذلك التحدث بالعامية في تعليم النحو وسائر علوم العربية 17. 11 معجم مقاييس اللغة، أحمد بن فارس أبو الحسن ت(395ه)، تح: عبد السلام محمد هارون، دار الفكر 1399هـ 1979م.

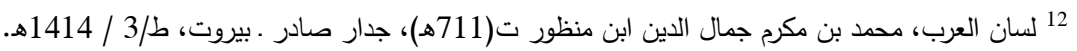

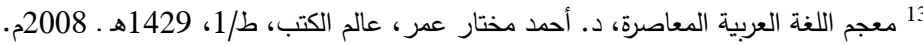

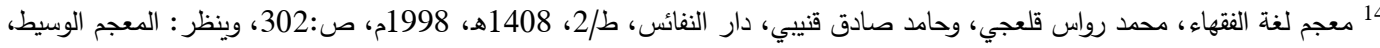

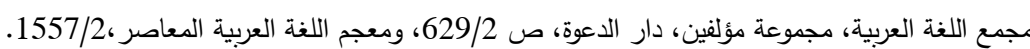
15 ينظر التحديات التي تواجه اللغة العربية ودور القرآن في التصدي لها، د. رياض محتئ، محود قاسم، وعبد الحميد الغراني، مؤتمر الإسلام والتحديات المعاصرة، كلية أصول الدين - الجامعة الإسلامية، 2007م، ص: 345.

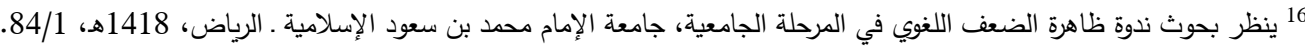
17 المصدر السابق: 84/1.

\section{IJHER}

International Journal of Humanities and Educational Research

Volume 1, Issue 1, December 2019, p.31-39 


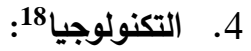

يعد هذا العامل ذات التأثير الأكبر في تراجع عملية القراءة والإقبال على الكتاب ومن ثمّ الاستعمال العامي

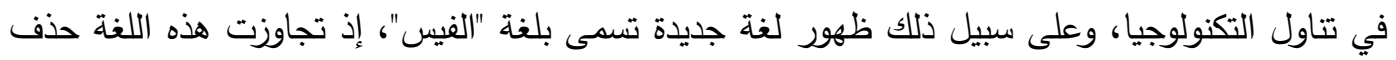
الحركات ليصل إلى حذف بعض الحروف من الكلمات أو قلبها أو إضافة حروف لها كإشباع بعض بلفة الحركات

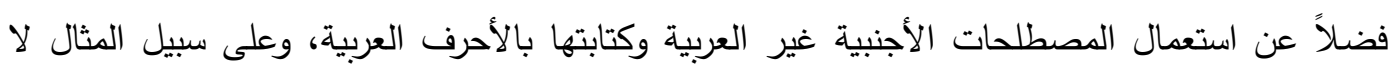
الحصر كتابة التتوين نوناً ساكنة، فنرى لفظة (شكراً) تكتب (شكرن)، وكذلك لفظة (رجاءً) تكتب (رجاءن)، ولفظة (فضلاً) تكتب (فضلن) إلى غير ذلك من الكلمات، وقديماً كانت المشكلة في كتابة الضاد والظاء ونكاء

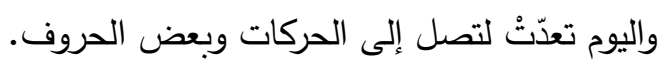

\section{المبحث الأول: في إهمال الإعراب 19}

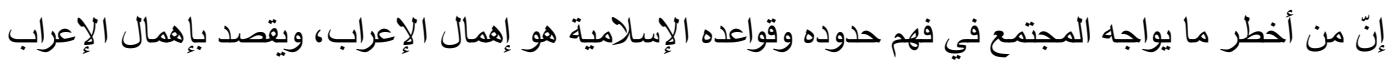

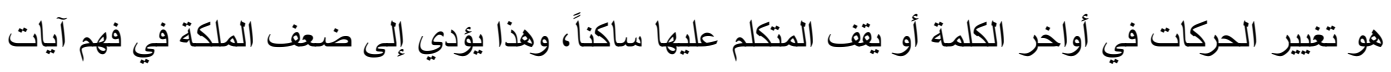

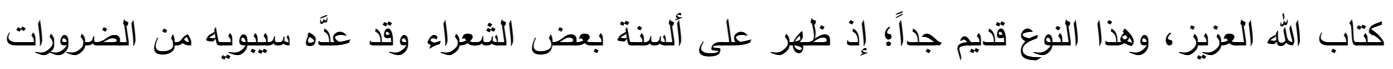
الثعرية.

إثماً من الله واغل.

وقد مثل سيبويه 20 لهذا قول امرئ القيس 21.

$$
\begin{aligned}
& \text { فأسكن الباء من الفعل (أشرب) وحقّه الضم. }
\end{aligned}
$$

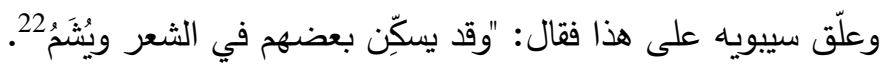

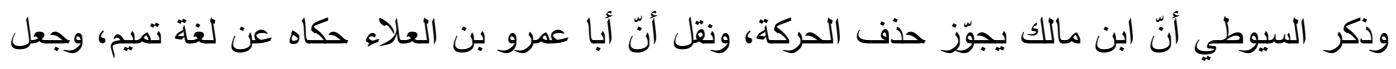

$$
\begin{aligned}
& \text { منه قوله تعالى (وبعولتُهن) بسكون التاء مُن. }
\end{aligned}
$$

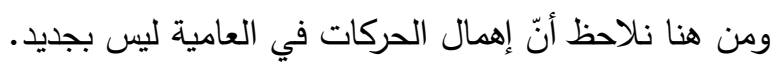

ولكن في الوقت نفسه ليس كحال اليوم في اتساعه، فقد تجاوز كل الحدود، وبات يسيطر على الألسنة حتى لهن

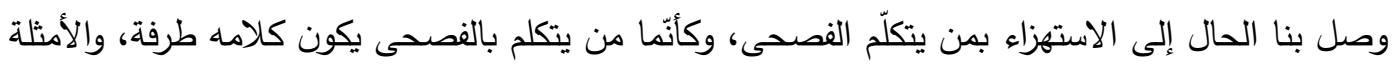
على هذا كثير ، ومن ذلك:

\footnotetext{
18 ينظر التحديات التي تواجه اللغة العربية.

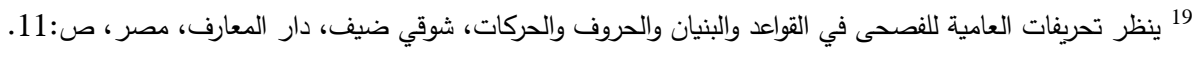

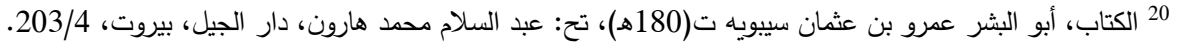

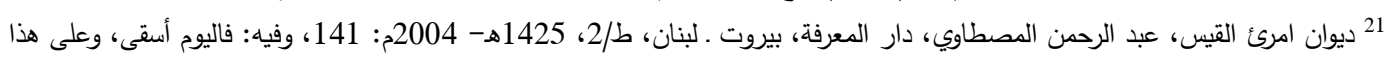
لا شاهد فيه يتضّح لنا ممتا ساقه سييويه. 22 الكتاب: 204/4. 23 ينظر همع الهوامع في شرح جمع الجوامع، جلال الدين عبد الرحمن بن أبي بكر السيوطي ت(911هـ)،تح: عبد الحميد هنداوي، الدكتبة التوقيفية، مصر ، ص:216/1.
}

\section{IJHER}

International Journal of Humanities and Educational Research

Volume 1, Issue 1, December 2019, p.31-39 
يحكى أنَّ شيخاً كان مفتشاً بالمدارس المصرية، قَدِم ذات يوم من رحلة تفتيثيّة له بمدارس الريف، وعندما

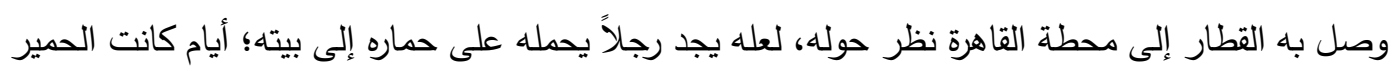

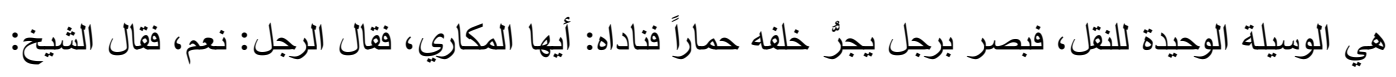
ائتي بحمار جمزى، فظنّ الرجل أنّه يتكلم لغة أجنبية فقرب منه، وجعل يستطلع جلية ما يريد حتى أخذ منه لونه الجهد، ولم يَخْظَ منه بطائل، وهنا ترك صاحب الحمار وذهب لحال سبيله وهرول الثيخ إلى بيته، وهو يقول:

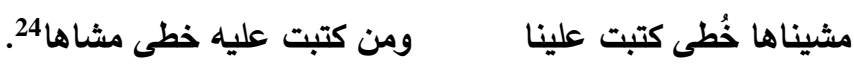

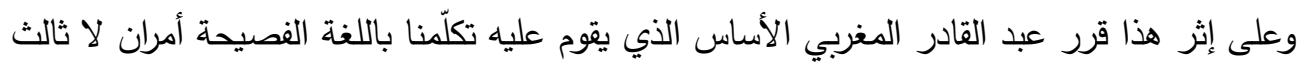
لهما

1. استعمال الكلمات العربية الفصيحة، وترك الكلمات العامية المبتذلة.

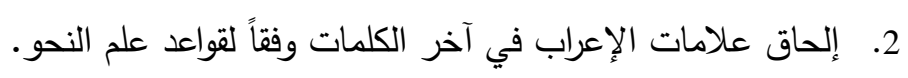
فإذا ما اعتمدنا هذا شيئا فشيئاً كانت النتائج ايجابية، وكانت الفرات الفحى هي السائدة في مجتمعاتتا.

\section{المبحث الثاني: دلالة الألفاظ العامية في الثريعة الإسلامية}

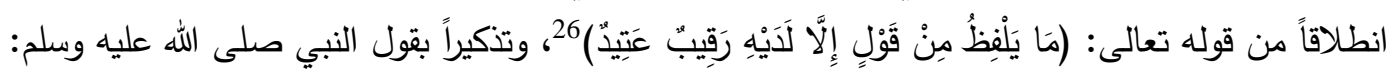

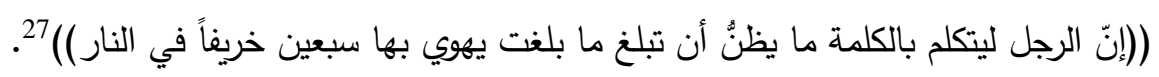

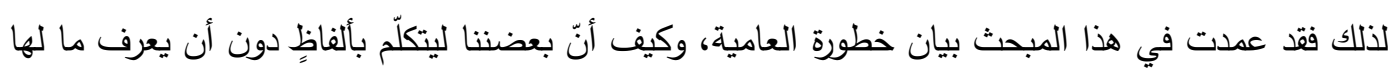

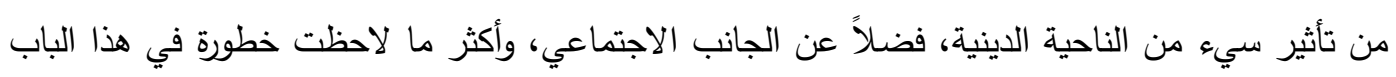

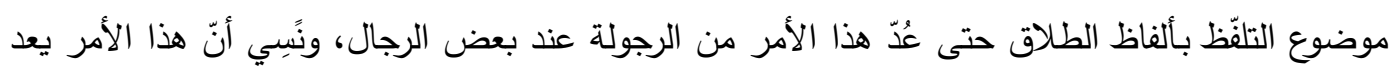

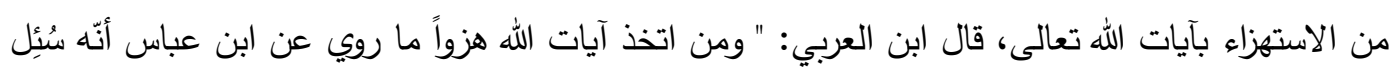

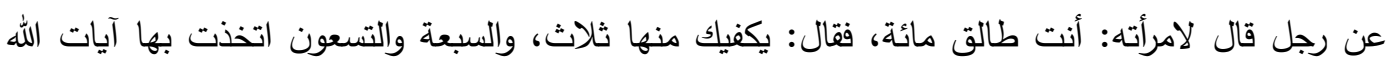
هزواً "28. ولذلك حذّر علماء الشريعة الإسلامية من الاستهانة بألفاظ الطلاق، وجريانها على الألسنة كجريان الماء في

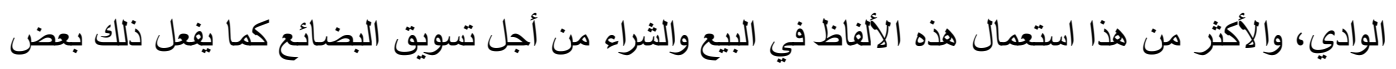

الجهلة. ومن الألفاظ العامية التي تتهى عنها الثريعة الإسلامية المتداولة بين الناس:

\footnotetext{
24 ينظر الثنائيات في قضايا اللغة العربية، د. نهاد الموسى، دار الثروق، عمان_ الأردن، ط/1، 2003م، ص:156. 25 المصدر السابق: 154. 26 سورة ق: الآية 18. 27 المستدرك على الصحيحين، أبو عبد الله الحاكم النيسابوري ت(405هـ) تح: مصطفى عبد القادر عطا، دار الكتب العلمية، بيروت، ط/1411، 1411هـ ـ 1990م، ص:640/40. 28 أحكام القرآن، أبو بكر محمد بن عبد الله ابن العربي، ت(543هـ):تح: محمد عبد القادر عطا، دار الفكر - لبنان، ص:271/1. 


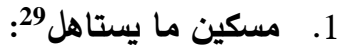

هذا يكثر عند حدوث المصيبة لثخص ما، وهذا اللفظ يعارض الإيمان بالقدر خيره وشره، قال تعالى: (مَا

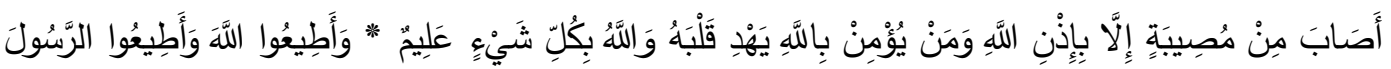

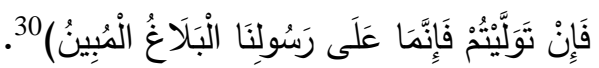
2. هذا اللفظ يفتح عمل الثيطان، وقد حذر النبي _صلى الله عليه وسلح_ من هذا فقال: ((وان أصابك شيء فلا

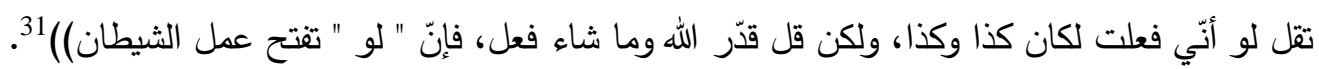
3. فلان خبيث: هذه من الأوصاف التي يكثر تداولها بين الناس، وهي من الألفاظ المستهجنة والأوصاف المستقبحة، وقد

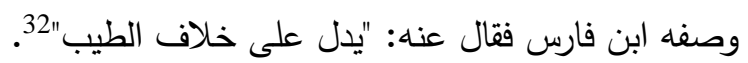
وقال الفيومي: (إنّ الخبيث يُطلق على الحرام كالزنا، وعلى الرديء المستكّره طعمه أو ريحه كالثوم والبصل،

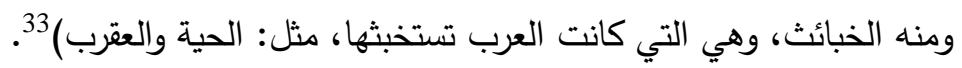
وقد نهى الرسول الكريم صلى الله عليه وسلم عن هذا اللفظ، فقال:

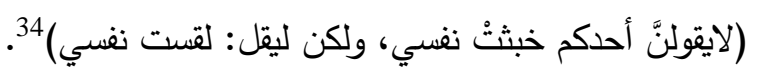

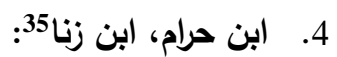

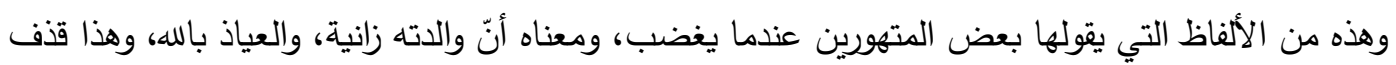

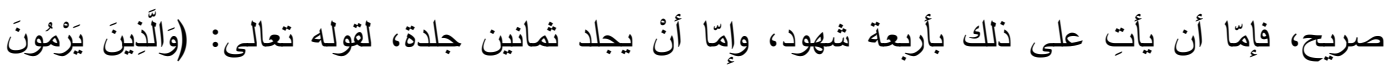

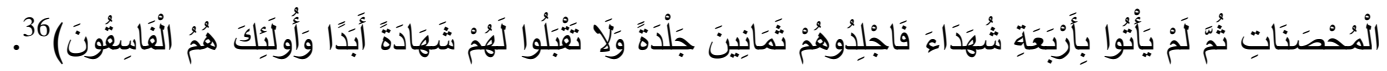

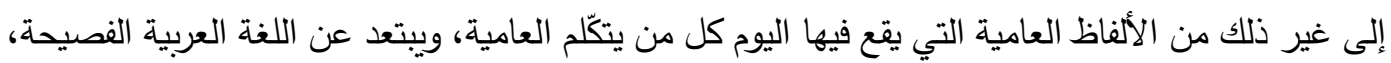
لغة القرآن الكريم والحديث النبوي الشريف. لعاميه

\footnotetext{
29 ينظر الأدلة الثرعية في بيان بطلان الألفاظ العامية في الثريعة الاعتقادية، محمد الجزائري الثاني، ص:2.

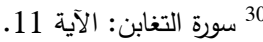
31 المسند الموضوعي الجامع لكتب العشرة، صهيب عبد الجبار، 169/3، والكتاب غير مطبوع. 238/2 مقاييس اللغة: 33 المصباح المنير في غريب الثرح الكبير، احمد بن محمد بن على الفيومي الحموي أبو العباس، ت(770هـ)، المكتبة العلمية، بيروت: ص162/1. 34 الأدب المفرد، محمد بن إسماعيل بن إبراهيم بن المغيرة البخاري أبو عبد الله، ت(256هـ)، تح: علي سمير بن أمين الزهيري، مكتبة المعارف،

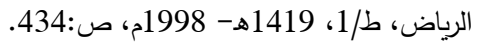
35 المستدرك على معجم المناهي اللفظية، سليمان بن صالح الخراشي، دار طيبة ـ الرياض، ط/236، 1419، 1427هـ ـ 2006م، ص:211.

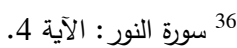

\section{IJHER}

International Journal of Humanities and Educational Research

Volume 1, Issue 1, December 2019, p.31-39 


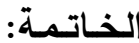

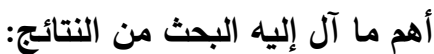

1. إنّ محاربة اللغة العربية ليست وليدة عصرنا هذا فالمؤامرات قديمة منذ أن ترأست الدولة الإسلامية المنطقة وقضت على الإمبراطورية الفارسية والرومية، والهدف من هذه المؤامرات قطع الاتصال بين المسلمين، والسعي إلى عزل الدول العربية وتجزئتها، وتدمير أهم مقومات وحدتها لغرض إضعافها والسيطرة على المنطقة بأكملها. 2. من اللافت للنظر أنّ الدعوة إلى إحلال العامية محل الفصحى يراد منه الابتعاد عن القرآن الكريم والسنة النبوية ومن ثمَّ الابتعاد عن فهم الأحكام التي توجه الإنسان نحو طريق الخير والرشاد.

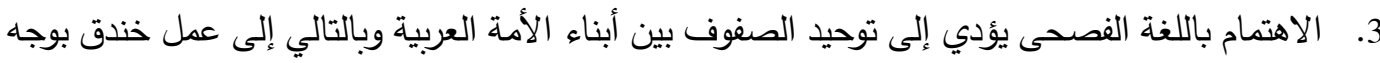
قوى الاستعمار التي تريد للمنطقة الدمار والتجزئة للسيطرة على خيراتها وبث الفقر فيها والتثرقة.

المصادر والـــــــــع أحكام القرآن، أبو بكر محمد بن عبد الله ابن العربي، ت(543هـ):تح: محمد عبد القادر عطا، دار الفكر ، لبنان.

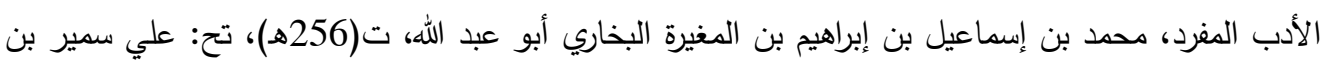

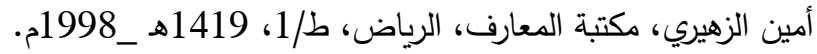

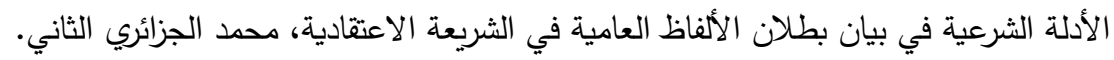

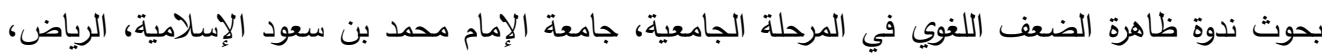
1418ه بحوث ومقالات في اللغة، رمضان عبد التواب، مكتبة الخانجي، القاهرة، ط/2، 1982م. تاريخ آداب اللغة العربية، جرجي زيدان، دار الهلال، القاهرة.

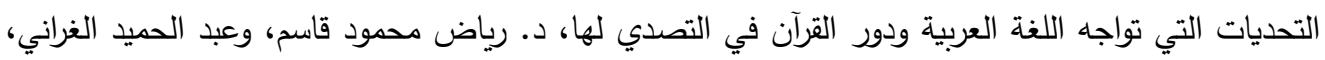
مؤتمر الإسلام والتحديات المعاصرة، كلية أصول الدين، الجامعة الإسلامية، 2007م. تحريفات العامية للفصحى في القواعد والبنيان والحروف والحركات، شوقي ضيف، دار المعارف، مصر .

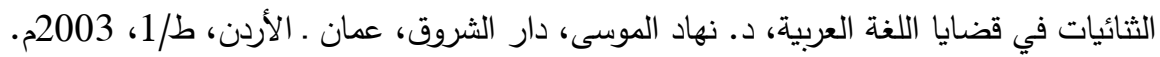

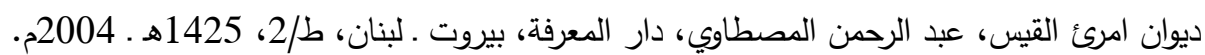
سوسيولوجيا اللغة، بيار أشار ، منشورات عويدات، بيروت_لبنان، ط/1، البن 1966م. الكتاب، أبو البشر عمرو بن عثمان سيبويه ت(180هـ)، تح: عبد السلام محمد هارون، دار الجيل، بيروت.

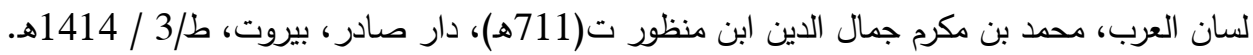
مجلة البحوث الإسلامية، اللغة العربية: لسان وكيان، أحمد محمد جمال، العدد الأول، الجزء الأول، الرئاسة

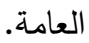
الإدارات البحوث العلمية والإفتاء والدعوة والإرشاد السعودية، 1395هـ.

\section{IJHER}


المستدرك على الصحيحين، أبو عبد الله الحاكم النيسابوري ت(405هـ) تح: مصطفى عبد القادر عطا، دار الكتب العلمية، بيروت، ط/1، 1411هـ_ 1990م.

المستدرك على معجم المناهي اللفظية، سليمان بن صالح الخراشي، دار طيبة ـ الرياض، ط/2، 1427هـ_ .2006

المصباح المنير في غريب الثرح الكبير، احمد بن محمد بن على الفيومي الحموي أبو العباس، ت(770هـ)، المكتبة العلمية، بيروت. معجم اللغة العربية المعاصرة، د. أحمد مختار عمر، عالم الكتب، ط/1، 1429هـ_ 2008م. المعجم الوسيط، مجمع اللغة العربية، مجموعة مؤلفين دار الاعوة. معجم لغة الفقهاء، محمد رواس قلعجي · حامد صادق قنيبي، دار النفائس، ط/2، 1408هـ_ 1998م.

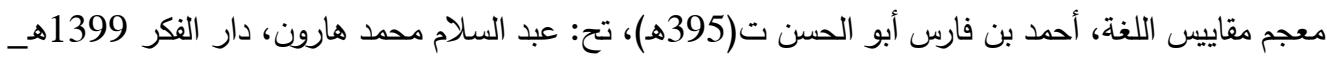
1979 همع الهوامع في شرح جمع الجوامع، جلال الدين عبد الرحمن بن أبي بكر السيوطي ت(911هـ)، تح: عبد الحميد هنداوي، المكتبة التوقيفية، مصر • 